\title{
Molecular Distribution Behavior of Cyanine Dyes in Aqueous Solution
}

\author{
David Baumann, Bryan Clark, Jared Garlick, and Hussein Samha \\ Department of Physical Science \\ Southern Utah University \\ Cedar City, Utah 84720 USA
}

Received: December 3, 2008

Accepted: January 30, 2009

\begin{abstract}
The molecular distribution of the cyanine dye (5-chloro-2-[3-[5-chloro-3-(4-sulfobutyl)-2(3H)benzothiazolylidine]-1-propenyl]-3-(4-sulfobutyl)-benzothiazolium hydroxide triethylamine salt, NK-3796) in aqueous solution was investigated using absorption and emission spectroscopy. Dimers of the dye are formed in concentrated solutions, while monomers dominate more diluted solutions. J aggregates are formed in solutions containing electrolytes such as sodium chloride, calcium chloride, and di-hydrogen ammonium phosphate. The dye readily forms $\mathrm{J}$ aggregates upon mixing with electrolyte. The $\mathrm{J}$ aggregates formation was followed spectroscopically by the appearance of a red-shifted narrow band centered at $653 \mathrm{~nm}$ in the absorption spectra. A similar shift is also observed in the emission spectra. The absorbance bandwidth is dependent on the charge of the cation of the electrolyte. This suggests different ground-state conformations for the $\mathrm{J}$ aggregates in solution.
\end{abstract}

\section{INTRODUCTION}

Self-assembled molecular aggregates bonding by non-covalent interactions have generated interest in the scientific community for their unique and unusual spectroscopic properties [1-4]. Cyanine dyes, in particular, have captured the attention of researchers over the last few decades because of their distinctive ability to form associations such as dimmers, $\mathrm{H}$ - and $\mathrm{J}$-aggregates in solution and on solid supporting surfaces [5-7]. J-aggregates are representative of polymer-type assemblies, which are composed of thousands of dye monomers [8]. Using various aqueous catalysts, J aggregates are formed readily. Their formation is accompanied by dramatic shifts in both absorbance and fluorescence maxima. Unique features such as optical storage and ultrafast optical switching [9, 10] provide the motivation to discover the properties of $\mathrm{J}$-aggregates and explore the mechanisms involved in their production.

This paper reports the self-assembly of the cyanine dye (NK-3796) shown in Figure 1 as a function of concentration in aqueous solution and also the production of $\mathrm{J}$-aggregates using inorganic electrolytes as catalysts.

\section{EXPERIMENTAL SECTION}

NK-3796 was purchased from Hayashibara Biochemical Laboratory, Inc. and used as received (99.5\% purity). A concentrated stock solution of $2.35 \times 10^{-5} \mathrm{M}$ (calculated using the molar absorptivity of $1.63 \times 10^{5}$ ) of the cyanine dye was prepared in water. To study the effect of the concentration of the dye on its molecular distribution in aqueous solution, diluted solutions $\left(1.18 \times 10^{-5} \mathrm{M}, 5.88 \times 10^{-6} \mathrm{M}\right.$, and $7.30 \times 10^{-7} \mathrm{M}$ ) were prepared from the stock 

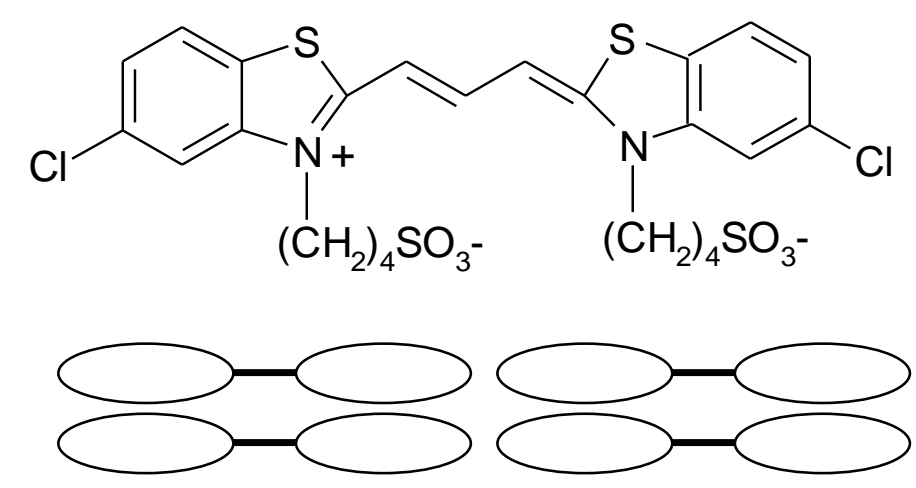

A schematic of $\mathrm{H}$-aggregates

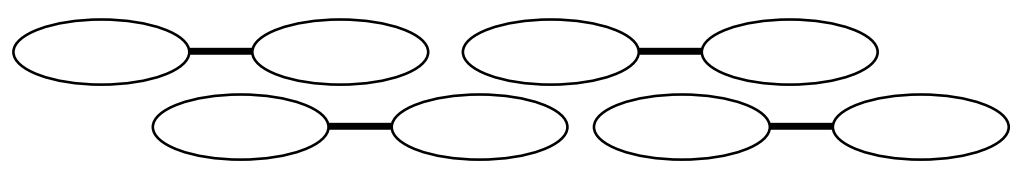

A schematic of $\mathrm{J}$-aggregates

Figure 1. Chemical structure of the cyanine dye (NK-3796) used in this study.

solution by adding the calculated amounts of water to portions of the stock solution. Then the absorbance and the emission of the dye in solution were recorded using an Agilent UV-Vis spectrophotometer for absorbance and a Photon Technology, Inc. (PTI) spectro-fluorometer for emission. A quartz cuvette with an optical path length of $0.1 \mathrm{~cm}$ was used to measure the absorbance of the dye in concentrated solutions.

The effect of different inorganic electrolytes on the aggregation behavior of the dye in solution was investigated by adding saturated electrolyte solutions to the calculated dye solution in the cuvette in micro-liter increments. For this purpose, a solution of the dye $\left(9.4 \times 10^{-6} \mathrm{M}\right)$ was used. Selected saturated aqueous solutions of sodium chloride, ammonium dihydrogen phosphate, and calcium chloride were added in $10 \mu \mathrm{L}$ increments. The absorbance of the dye in solution was recorded before the electrolyte was added and also after each added increment. The addition of the electrolyte solution continued until there was no further change in the absorbance of the dye.

\section{RESULTS AND DISCUSSION}

The effect of dye concentration on the, monomer $\leftrightarrows$ dimer, equilibrium distribution in aqueous solution is illustrated in Figure 2. The absorbance of the dye in a moderately concentrated solution $\left(\sim 10^{-5} \mathrm{M}\right)$ exhibits a major absorbance peak centered at $519 \mathrm{~nm}$ corresponding to the dimer and a lesser intense peak centered at $563 \mathrm{~nm}$ correspond to the monomer. Clearly, the absorbance suggests the formation of dimmers as the concentration of the dye in solution increases. In a very dilute solution $\left(\sim 10^{-7} \mathrm{M}\right)$ the dye in highest concentration is in monomeric form. As the concentration of the dye increased $\left(\sim 10^{-4} \mathrm{M}\right)$, a new broad blue shifted peak centered at $500 \mathrm{~nm}$ developed with a shoulder around $508 \mathrm{~nm}$. The shoulder matches the dimer while the broad absorption is caused by a new species that resemble $\mathrm{H}$-aggregates. Comparing the meso-substituent (in the 9 position) on the chromophore with un substituted dye illustrates the effect on the molecular distribution of the dye in aqueous solution. It has been reported that ethyl substituted dye forms $\mathrm{J}$ aggregates and methyl substituent forms either $\mathrm{H}$ or $\mathrm{J}$ aggregates at higher concentration [4]. The present un-substituted dye produced a mixture of dimer/H aggregates, which upon addition of an electrolyte it converts completely to $\mathrm{J}$ aggregates. The addition of a saturated sodium chloride aqueous solution, at $10 \mu \mathrm{L}$ increments, to a diluted 


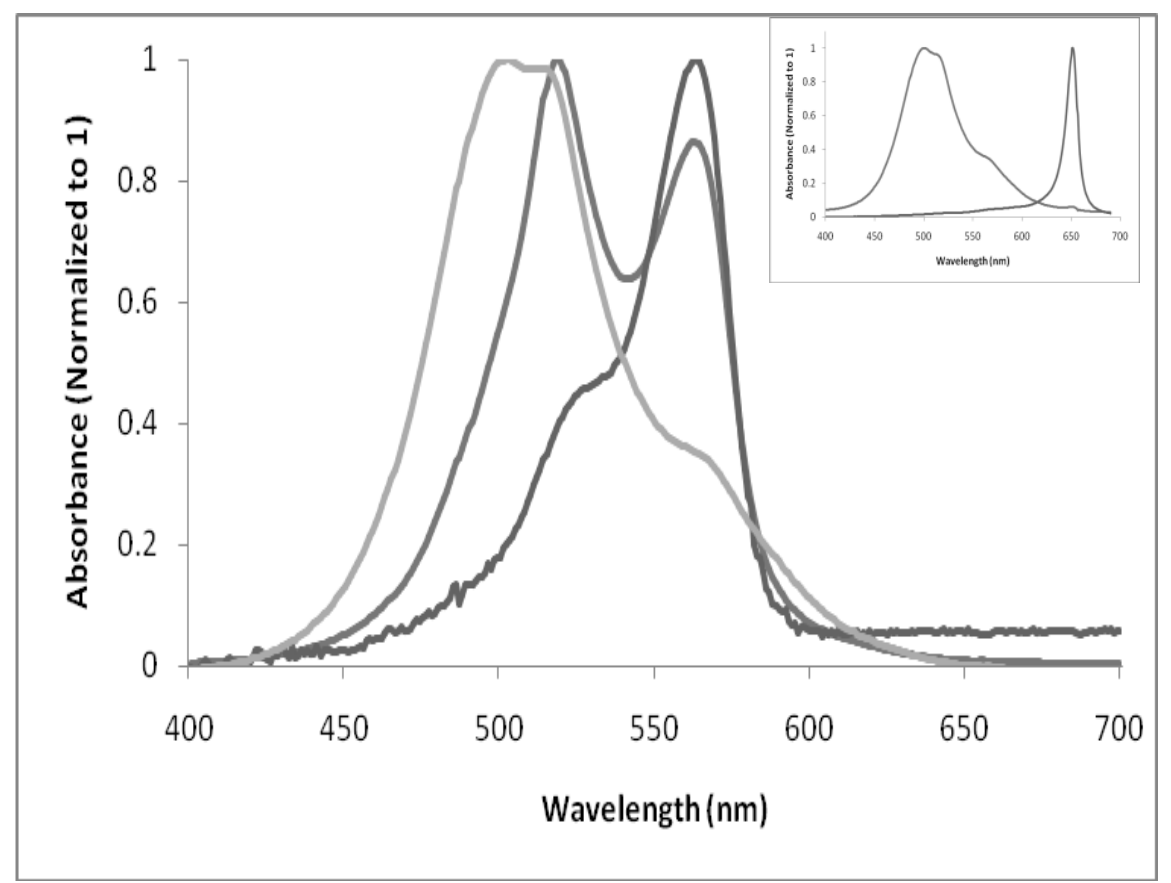

Figure 2. Absorbance spectra of NK-3796 $\left(2.35 \times 10^{-5} \mathrm{M}\right)$ (medium gray), $\left(7.30 \times 10^{-7} \mathrm{M}\right)$ (dark gray), and $\left(\sim 10^{-4} \mathrm{M}\right)$ (light gray).

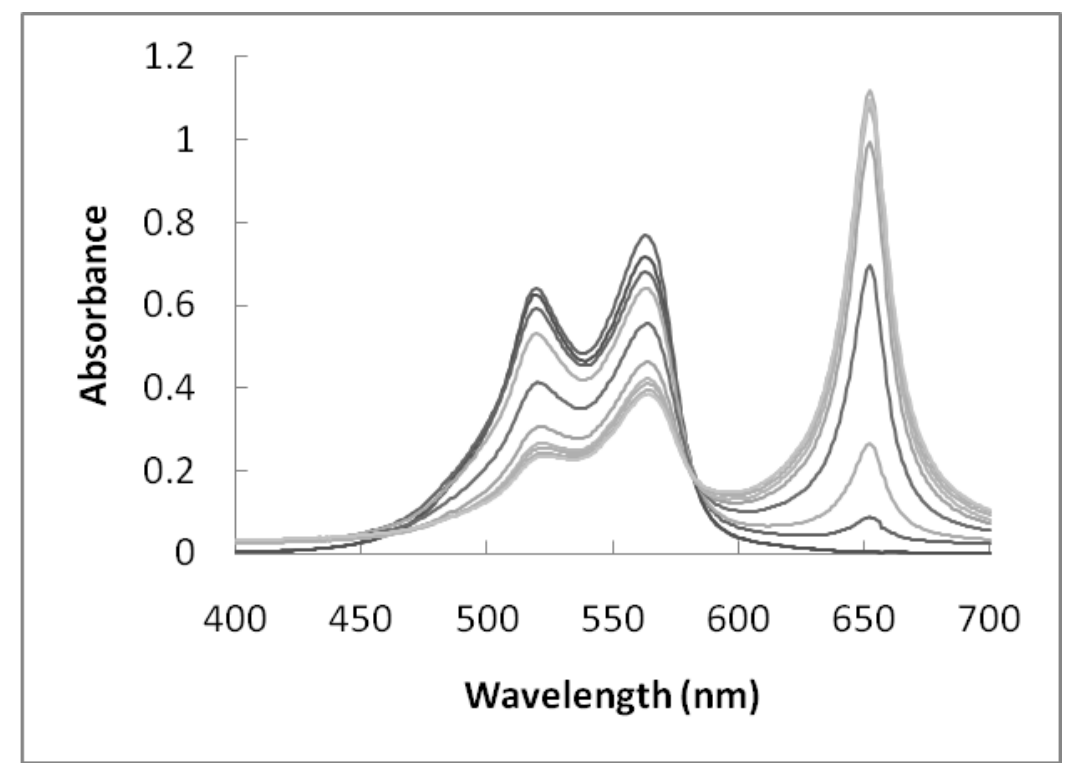

Figure 3. Absorbance spectra of NK-3796 $\left(9.40 \times 10^{-6} \mathrm{M}\right)$ after addition of $10 \mu \mathrm{L}$ of sodium chloride saturated solution incrementally. Maximum aggregation was formed at $4.27 \times 10^{-4} \mathrm{mM}$ sodium chloride. 


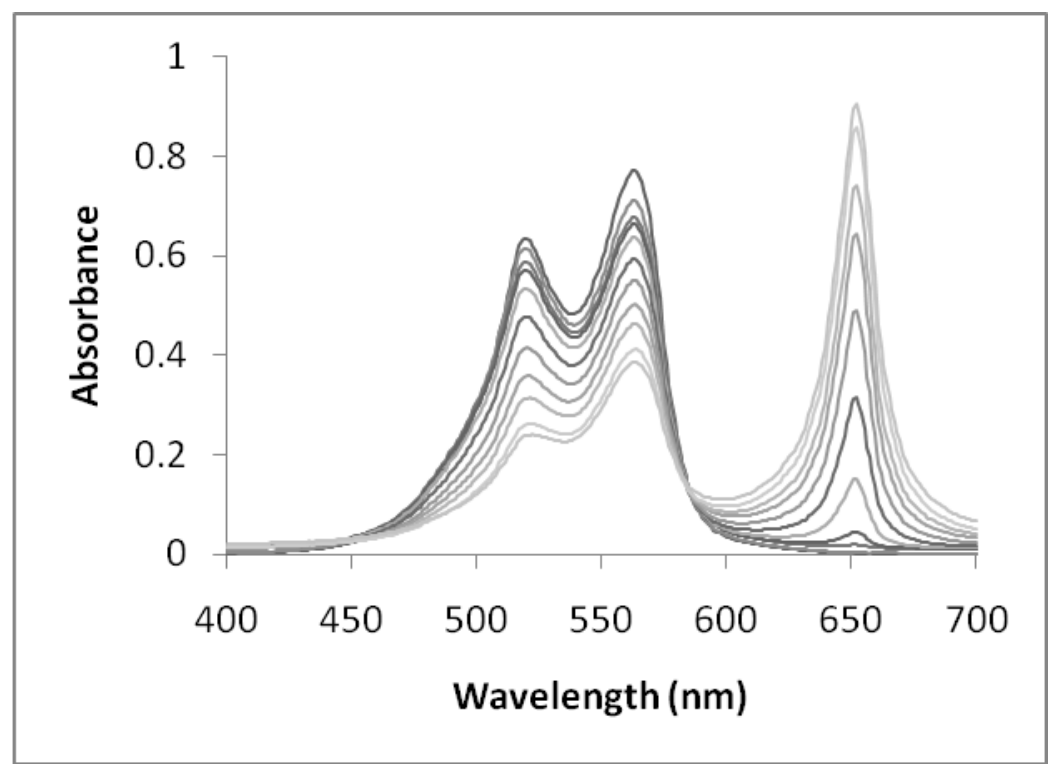

Figure 4. Absorbance spectra of NK-3796 $\left(9.40 \times 10^{-6} \mathrm{M}\right)$ after addition of $10 \mu \mathrm{L}$ of ammonium dihydrogen phosphate saturated solution incrementally. Maximum aggregation was formed at $1.68 \times 10^{-4} \mathrm{mM}$ ammonium dihydrogen phosphate.

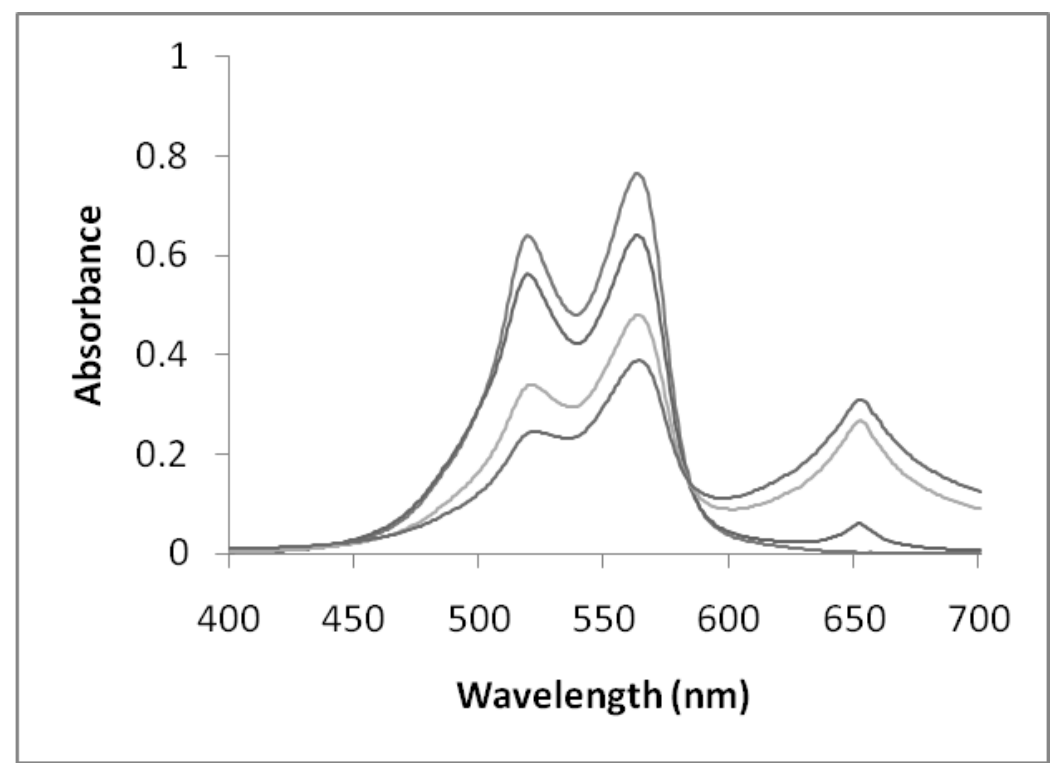

Figure 5. Absorbance spectra of NK-3796 $\left(9.40 \times 10^{-6} \mathrm{M}\right)$ after addition of $10 \mu \mathrm{L}$ of calcium chloride saturated solution incrementally. Maximum aggregation was formed at $1.97 \times 10^{-4} \mathrm{mM}$ calcium chloride.

$\left(\sim 10^{-6} \mathrm{M}\right)$ solution of the dye, where only monomers exist in solution, resulted in the appearance of a small but significant shoulder peak centered at $653 \mathrm{~nm}$. This shoulder continued to develop into a sharppeak upon the addition of more sodium chloride solution (Figure 3). The formation of this red-shifted absorbance suggests the formation of J-aggregates in solution. Maximum aggregation occurred at a sodium chloride concentration of $2.8 \times 10^{-2} \mathrm{~g} / \mathrm{mL}$. 
Similar results were obtained when ammonium dihydrogen phosphate was added to the same stock solution of the dye (Figure 4). Since the common ion between sodium chloride and ammonium dihydrogen phosphate is the sodium ion, the results suggest that the nature of the cation of the electrolyte and its charge are the two major factors that affect the type of $\mathrm{J}$ aggregates obtained.

The addition of a saturated sodium chloride aqueous solution, at $10 \mu \mathrm{L}$ increments, to a diluted $\left(\sim 10^{-6} \mathrm{M}\right)$ solution of the dye, where only monomers exist in solution, resulted in the appearance of a small but significant shoulder peak centered at $653 \mathrm{~nm}$. This shoulder continued to develop into a sharp-peak upon the addition of more sodium chloride solution (Figure 3 ). The formation of this red-shifted absorbance suggests the formation of $\mathrm{J}$-aggregates in solution. Maximum aggregation occurred at a sodium chloride concentration of $2.8 \times 10^{-2}$ $\mathrm{g} / \mathrm{mL}$.

Similar results were obtained when ammonium dihydrogen phosphate was added to the same stock solution of the dye (Figure 4). Since the common ion between sodium chloride and ammonium dihydrogen phosphate is the sodium ion, the results suggest that the nature of the cation of the electrolyte and its charge are the two major factors that affect the type of $\mathrm{J}$ aggregates obtained.

Similarly, the addition of calcium chloride saturated solution to the dye produced the $\mathrm{J}$ aggregates (Figure 5). Unlike the previous two experiments, the $\mathrm{J}$ band became broader with the use of calcium chloride. This broadness of the $\mathrm{J}$ band is attributed to the formation of $\mathrm{J}$ aggregates that have different ground state configuration [11].

\section{CONCLUSIONS}

In concentrated solutions of the dye $\left(>\sim 10^{-5} \mathrm{M}\right.$ ) , dimers predominate, while in diluted solutions the monomeric form is in highest concentration. No pure $\mathrm{H}$ aggregates were detected in more concentrated solution (up to $10^{-4} \mathrm{M}$ ). J aggregates are formed upon addition of inorganic electrolytes. Quantitative transformation of both the dimers and the monomers of the dye into $\mathrm{J}$ aggregates was achieved by adding electrolytes containing +1 cations, such as sodium chloride and ammonium dihydrogen phosphate. The Jaggregates formed upon addition of electrolytes with +2 cations, such as calcium chloride have a different ground state confirmation. Thus, the production of aggregates in solution, depends primarily on the cation charge but not the size.

\section{REFERENCES}

1. Arindam Chowdhury, Sebastian Wachsmann-Hogiu, Prakriti R. Bangal, Izzat Raheem, and Linda A. Peteanu, J. Phys. Chem. B., 105 (2001), page 12196.

2. Gilman, P. B. J. Photoger. Sci. Eng., 18 (1974), page 418.

3. Wang, Y. Chem. Phys. Lett., 126 (1986), page 209.

4. Hiroshi Yao, Takeshi Isohashi, and Keisaku Kimura, J. Phys. Chem. B., 111 (2007), page 7176.

5. Hada, H.; Hanawa, R.; Haraguchi, A.; Yonezawa, Y. J. Phys. Chem., 89 (1985), page 560.

6. Misawa, K.; Ono, H.; Minoshima, K.; Kobayashi, T. Appl. Phys. Lett., 63 (1993), page 577.

7. Sluch, M. I.; Vitukhonovsky, A. G.; Yonezawa, Y.; Sato, T.; KKunisawa, T. Opt. Mater., 6 (1996), page 261.

8. Slavnova, Tatyana $\mathrm{D}$; Chibisov, Alexander K, J. Phys. Chem. A. (2005), page 4758.

9. Wu, Jian-Jun; Li, Na; Li, Ke-An; Liu, Feng, J. Phys. Chem. B. (2008), page 8134.

10. A. Dixon; C. Duncan; H. Samha, American Journal of Undergraduate Research, 3 (4) (2005), page 29.

11. Noritsugu, K.; Hiroyoshi, N.; Kenji, A.; Yoshiro, Y.; Okitsugu, K. J. Phys. Chem. B. 104 (2000), page 9630; and references therein. 


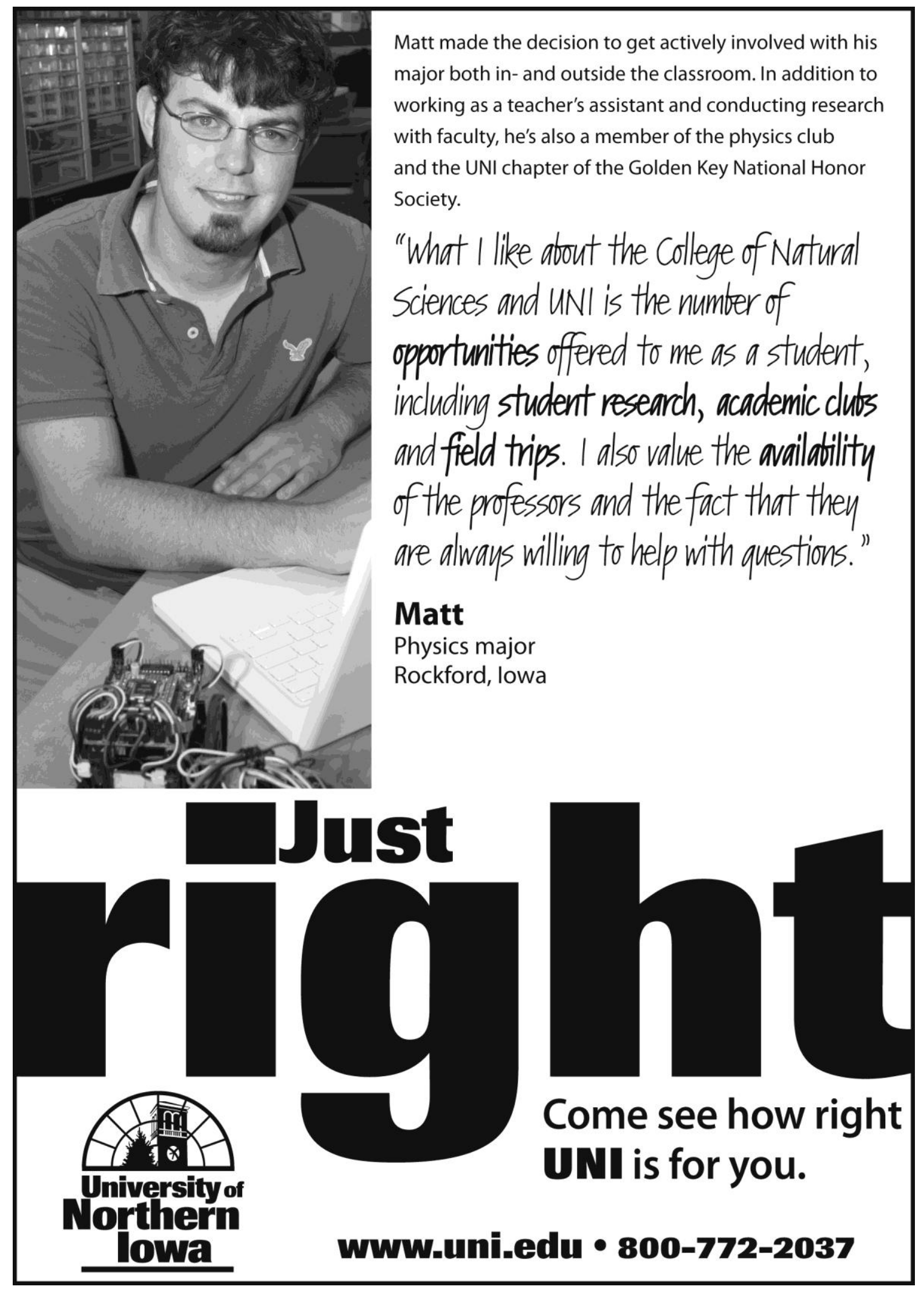

